\title{
Estimasi Kedalaman Akuifer Dangkal Daerah TPA Manggar dengan Menggunakan Metode Geolistrik Konfigurasi Wenner
}

\author{
Febrian Dedi Sastrawan ${ }^{*}$, Jakaria Asfan Latifan ${ }^{2}$ \\ ${ }^{1,2}$ Program Studi Fisika, Jurusan Sains Teknologi Pangan dan Kemaritiman, \\ Institut Teknologi Kalimantan \\ febrian.dedi@itk.ac.id
}

\begin{abstract}
Research on the estimation of shallow aquifer depth is very useful to determine the distribution of shallow aquifer potential that can be utilized by humans easily and efficiently. The research methods include the study of geological conditions, using Wenner electrical resistivity and interpretation of cross-section $2 D$ subsurface resistivity to determine the estimation of shallow aquifer depths. Based on variations in resistivity values in $2 D$ cross sections, it can be seen the subsurface conditions of the study area consisted of clay layers with resistivity values of 5-20 ohms, sand layers with resistances of 20 - $70 \mathrm{ohms}$ meters, layers of soil and limestone insertion with resistivity 70 - 300 ohms. The sand layer acts as an aquifer because it can storeand transmit water. At the study site, the sand layer is at a depth of 5-10 meters which has the potential as a shallow aquiferclassified as a unconfined aquifer
\end{abstract}

Keywords: resistivity, aquifer, wenner, geoelectrical

\begin{abstract}
Abstrak
Penelitian mengenai estimasi kedalaman akuifer dangkal sangat berguna untuk mengetahui sebaran potensi akuifer dangkal yang dapat dimanfaatkan oleh manusia secara mudah dan efisien. Metode penelitian meliputi studi mengenai kondisi geologi, pengukuran geolistrik konfigurasi wenner dan interpretasi penampang 2D resistivitas bawah permukaan untuk mengetahui estimasi kedalaman akuifer dangkal. Berdasarkan variasi nilai resistivitas dalam penampang 2D dapat diketahui kondisi bawah permukaan daerah penelitian terdiri darilapisan lempung dengan nilairesistivitas 5-20 $\Omega \mathrm{m}$, lapisan pasir dengan resisitivitas $20-70 \Omega \mathrm{m}$, lapisan soil dan sisipan batu gamping dengan resistivitas $70-300 \Omega \mathrm{m}$. Lapisan pasir berperan sebagai akuifer karena dapat menyimpang dan meyoloskan air. Pada lokasi penelitian lapisan pasir berada pada kedalaman 5-10 meter yang berpotensi sebagai akuifer dangkal yang tergolong sebagai akuifer bebas.
\end{abstract}

Kata kunci : resistivitas, akuifer, wenner, geolistrik

\section{Pendahuluan}

\subsection{Air Tanah}

Air merupakan kebutuhan utama dalam kehidupan, semua makhluk hidup membutuhkan air untuk bertahan hidup. Bumi menyediakan pasokan air yang sangat melimpah, berdasarkan tempatnya air di bumi dibagi menjadi, yaitu air permukaan dan air tanah. Air permukaan adalah air yang berada di atas permukaan tanah dan dapat terlihat langsung. Sedangkan air tanah adalah air yang meresap ke lapisan bawah tanah [1].
Berdasarkan letaknya air tanah terbagi menjadi dua jenis [2].

a) Air tanah dangkal adalah air tanah yang terletak tidak jauh dari permukaan tanah serta berada di atas lapisan kedap air. Jenis air tanah ini banyak digunakan oleh masyarakat untuk memenuhi kebutuhannya.

b) Air tanah jenis artesis adalah air tanah yang terletak diantara lapisan kedap air dan biasa terdapat jauh dibawah permukaan tanah, sehingga butuh biaya 
yang lebih besar untuk mendapatkan air tanah ini.

Kebutuhan air tanah saat ini meningkat seiring dengan peningkatan jumlam penduduk. Usaha yang dapat dilakukan memenuhi kebutuhan air tanah tersebut perlu di lakukan penelitian untuk mengetahui sebaran dan potensi akuifer dangkal disekitar lokasi penelitian. Penelitian yang telah banyak dilakukan adalah survey air tanah denga menggunakan metode geolistrik. Metode geolistrik memanfaatkan sifat kelistrikan yaitu resistivitas suatu medium untuk mengetahui kondisi bawah permukaan. Nilai resistivitas dapat digunakan untuk mengetahui kondisi bawah permukaan karena Lapisan dengan tekstur keras dicirikan dengan nilai resistivitas yang tinggi sebaliknya lapisan yang memiliki kandungan fluida didalamnya akan cenderung memiliki nilai resistivitas rendah [3]. Penelitian ini menggunakan konfigurasi Wenner untuk memperoleh penampang 2D resistivitas bawah permukaan untuk mengestimasi kedalaman lapisan akuifer dangkal.

\subsection{Metode Geolistrik}

Geolistrik adalah salah satu metode geofisika yang mempelajari sifat kelistrikan medium dalam hal ini bumi dianggap sebagai suatu medium raksasa [4]. Metode geolistrik melakukan pendeteksian bawah permukaan dengan memanfaatkan sifat resistivitas lapisan bawah permukaan.

Metode geolistrik menggunakan asumsi bumi sebagai medium yang dilalui oleh arus listrik memiliki lapisan yang sama atau homogen [5]. Berdasarkan asumsi ini nilai resistivitas yang diperoleh merupakan nilai resistivitas sebenarnya dan tidak bergantung pada jarak elektroda yang digunakan dalam penelitian. Kondisi real dibawah permukaan berlawan dengan asumsi yang digunakan dimana lapisan bawah permukaan terdiri atas banyak lapisan. Hal ini menyebabkan besar nilai resistivitas yang diperoleh merupakan akumulasi dari resistivitas setiap lapisan yang alah dibawah permukaan bumi. Karena nilai resistivitas yang di peroleh dianggap sebagai nilai resistivitas satu lapisan saja, sehingga di sebut sebagai resistivitas semu.

Besar resistivitas semu dapat diperoleh dengan menggunakan persamaan

$$
\rho_{a}=K \frac{\Delta V}{I}
$$

Dimana $\Delta V$ adalah nilai potensial yang terukur, $I$ adalah arus yang di injeksikan kebawah permukaan bumi dan $K$ adalah factor geometri.

Salah satu konfigurasi yang banyak digunakan dalam survey geolistrik adalah konfigurasi wenner yang termasuk dalam metode survey mapping. Hasil survey menggunakan konfigurasi wenner menghasilkan penampang lateral 2D resistivitas bawah permukaan. Konfigurasi wenner sangat baik digunakan untuk survey akuifer dangkal karena dapat memberikan informasi kedalaman dan sebaran lapisan akuifer dangkal[6]. Berikut adalah susunan elektroda konfigurasi wenner (gambar 1)

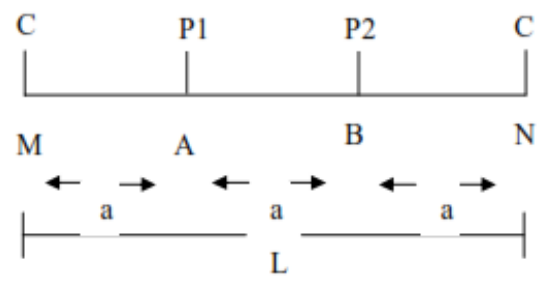

Gambar 1. Konfigurasi Wenner[7]

\subsection{Geologi Daerah Penelitian}




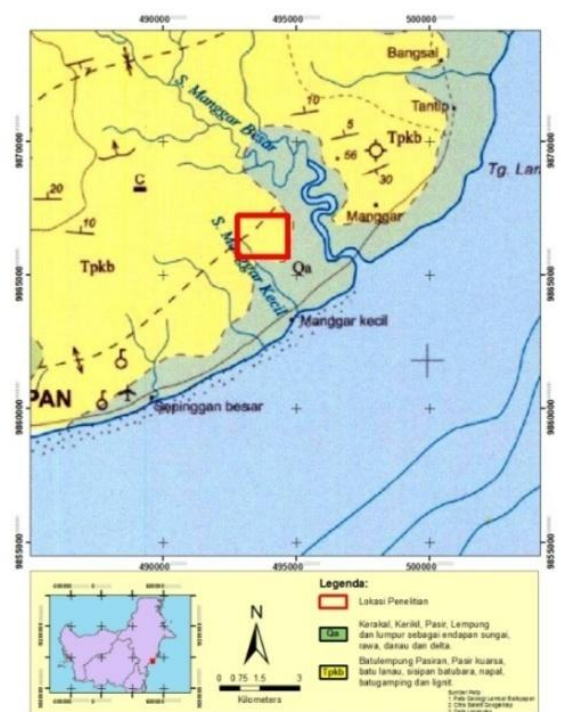

Gambar 2. Geologi daerah penelitian

Berdasarkan gambar 2 daerah penelitian berada pada Formasi Kampung Baru. Jenis batuan dalam Formasi Kampung Baru terdiri dari Batulempung, pasir, lanau, sisipan batubara, napal, lignit dan batugamping (Hidayat, 1994). Sturuktur lapisan batuan dalam Formasi ini tidak menerus hanya terdapat pada daerah - daerah tertentu. Formasi Kampung baru diendapkan di Lingkungan laut dangkal dan delta. Formasi ini terletak tidak selaras di atas Formasi Balikpapan.

Terdapat struktur antiklin yang menyebabkan topografi daerah penelitian berundulasi dan memiliki kemiringan hingga $45^{\circ}$. Lapisan tanah penutup daerah penelitian merupakan tanah podsolik merah yang umumnya terdapat hampir diseluruh daerah Balikpapan. Kemiringan lapisan batuan pada daerah penelitian adalah $10^{\circ}-20^{\circ}$ dengan strike lapisan batuan hampir mengarah Barat Timur.

Berdasarkan jenis batuan formasi Kampung Baru memiliki potensi akuifer yang baik. Lapisan batuan yang memiliki potensi sebagai lapisan akuifer baik adalah lapisan pasir dengan porositas dan permeabilitas yang tinggi. Selian intu juga terdapat potensi batubara yang cukup baik dengan ketebalan lapisan batubara pada formasi ini 2-3 m.

\section{Metoda Penelitian}

Metode pengukuran dalam penelitian ini terdiri dari studi pustakan mengenai kondisi geologi daerah penelitian untuk memberikan gambaran awal tentang kondisi bawah permukaan daerah penelitian. Hasil studi geologi digunakan untuk membantu dalam tahap interpretasi penampang 2D resistivitas bawah permukaan.

Pengukuran geolistrik konfigurasi wenner dengan panjang bentangan sejauh 150 meter dengan arah lintasan Timur Laut - Barat Daya. Lokasi penelitian ditunjukan pada gambar 3 . Dilakukan pengukuran sebanyak 3 lintasan pengukuran. Area peneltian berada pada posisi X 493439 - X 494074 dan Y 9866340 - Y 9866580. Susunan konfigurasi wenner sesuai dengan gambar 1.

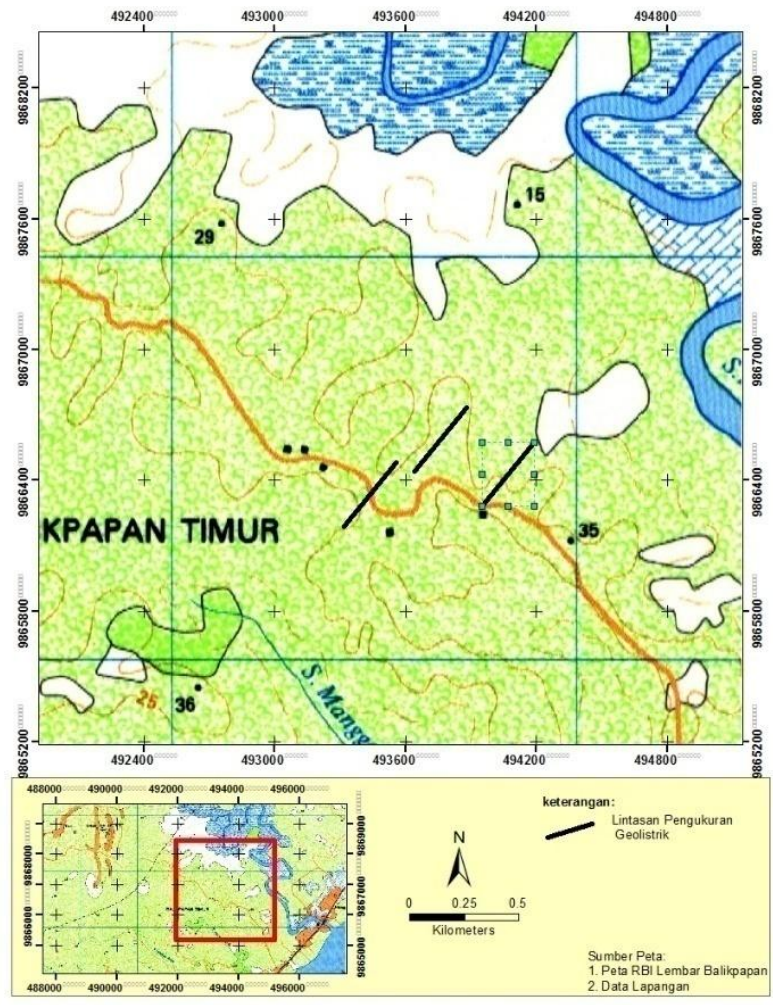

Gambar 3. Lokasi penelitian

Hal yang dilakukan untuk mengetahui respon bawah permukaan terhadap arus listrik adalah dengan mengijeksikan arus kebawah permukaan melalui elektroda arus yang tertancap di permukaan. Setelah diinjeksikan 
arus listrik akan muncul beda potensial diantara dua titik elektroda potensial.

Data yang diperoleh dalam penggukuran adalah besar arus yang diinjeksikan dan nilai beda potensial serta nilai faktor geometri dari konfigurasi wenner. Data tersebut digunakan untuk menghitung besar nilai resistivitas semu bawah permukaan.

Hal yang dilakukan untuk mengetahui respon bawah permukaan terhadap arus listrik adalah dengan mengijeksikan arus kebawah permukaan melalui elektroda arus yang tertancap di permukaan. Setelah diinjeksikan arus listrik akan muncul beda potensial diantara dua titik elektroda potensial.

Data yang diperoleh dalam penggukuran adalah besar arus yang diinjeksikan dan nilai beda potensial serta nilai faktor geometri dari konfigurasi wenner. Data tersebut digunakan untuk menghitung besar nilai resistivitas semu bawah permukaan.

Nilai resistivitas semu digunakan dalam pengolahan dengan menggunakan software inversi untuk memperoleh nilai resistivitas sebenarnya. Hasil inversi akan menunjukanPerbedaan antara nilai resistivitas semu dan resistivitas sebenarnya disebut sebagai RMS error. Nilai RMS error tidak selalu harus kecil tetapi dapat dianggap optimal jika model 2D resistivitas bawah permukaan sudah dianggap sesuai dengan kondisi geologi daerah penelitian [8]. Hasil dari pengolahan adalah penampang $2 \mathrm{D}$ resistivitas bawah permukaan yang dapat diinterpretasikan sebagai susunan lapisan batuan bawah permukaan berdasarkan informasi geologi dan nilai resistivitas bawah permukaan untuk mengetahui estimasi kedalaman akuifer dangkal.

\section{Hasil Penelitian}

Hasil dalam penelitian ini adalah penampang 2D resistivitas bawah permukaan hasil inversi dengan menggunakan software inversi. Penampang 2D resistivitas bawah permukaan menunjukan distribusi nilai resistivitas dibawah permukaan. Nilai resistivitas bawah permukaan yang di peroleh berkisar 5 - $300 \Omega$ m sesuai dengan gambar 2,3 dan 4.

Hasil pengolahan data menggunakan software inverisi memberikan nilai resistivitas bawah permukaan sebenarnya berdasarkan nilai resisitivitas semu hasil perhitungan dengan menggunakan data pengukuran. Nilai resistivitas semu dan resistivitas sebenarnya akan berbeda karena lapisan bawah permukaan tidak homogen.

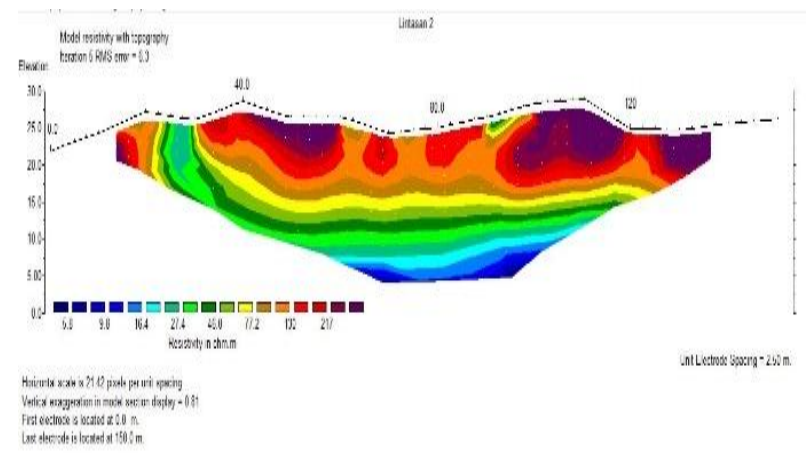

Gambar 4. Penampang 2D resistivitas lintasan 1

Gambar 4 menujukan penampang 3D resistivitas bawah permukaan lintasan satu. Terlihat distribusi nilai resitivitas yang merata disepanjang lintasan pengukuran. Berdasarkan nilai resistivitas bawah permukaan dapat diketahui susunan lapisan batuan bawah permukaan lokasi penelitian. Lapisan pertama adalah soil yang terdiri dari tanah timbunan jalan yang tersusun dari material batuan keras dengan nilai resitivitas 70-300 $\Omega \mathrm{m}$. Lapisan kedua diduga sebagai lapisan pasir pada kedalaman 5-10 m dengan nilai resistivitas 20$70 \Omega \mathrm{m}$. lapisan pasir dapat menyimpan dan meloloskan air karena memiliki pori-pori batuan yang saling terhubung dengan baik. Lapisan pasir diduga sebagai lapisan akuifer dangkal yang terdapat pada lintasan satu. Lapisan ketiga diduga sebagai lapisan lempung dengan nilai resistivitas 5-20 $\Omega \mathrm{m}$, lapisan ini berfungsi sebagai lapisan impermeable dibawah lapisan akuifer dangkal. 


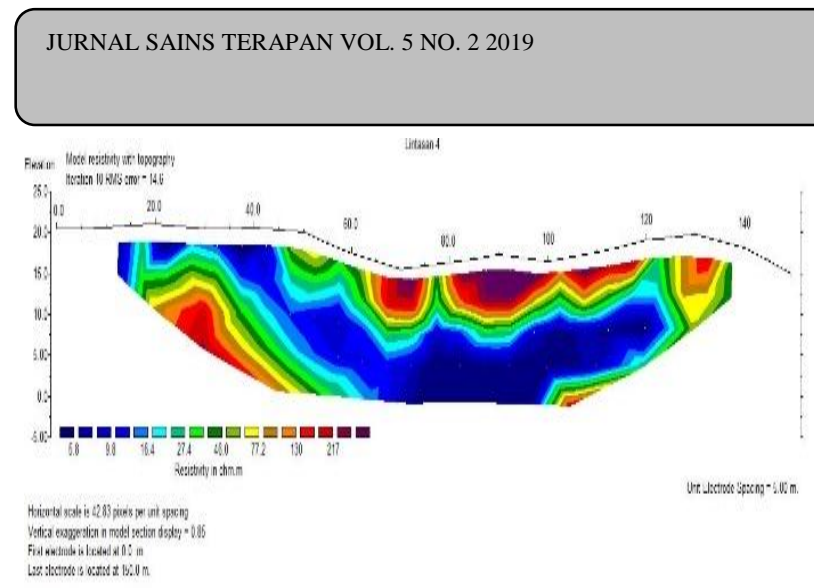

Gambar 5. Penampang 2D resistivitas lintasan 2

Hasil pengolahan data pada lintasan kedua menunjukan distribusi nilai resistivitas bawah permukaan. Pada lintasan kedua susunan lapisan bawah permukaan tersusun atas lapisan soil dan pasir kuarsa dengan nilai resistivitas 70-300 $\Omega \mathrm{m}$. Lapisan kedua diduga sebagai lapisan lempung dengan nilai resisitivitas 5-20 $\Omega \mathrm{m}$ pada kedalaman 10-25 m. Bagian permukaan pada jarak 0-40 m terlihat nilai resistivitas rendah dikarena kondisi lapangan mengandung air, hal ini menyebabkan seakan-akan lapisan lempung menerus hingga kepermukaan. Lapisan ketiga terdiri dari sisipan batugamping dengan resistivitas 200-300 $\Omega \mathrm{m}$ dan lapisan pasir dengan nilai resistivitas $20-70 \Omega \mathrm{m}$ pada kedalaman 5-25 meter. Lapisan pasir pada lintasan kedua berada diatas sisipan batu gamping pada jarak 0-60 m pada lintasan kedua. Lapisan pasir ini diduga sebagai akuifer dangkal pada lintasan ini.

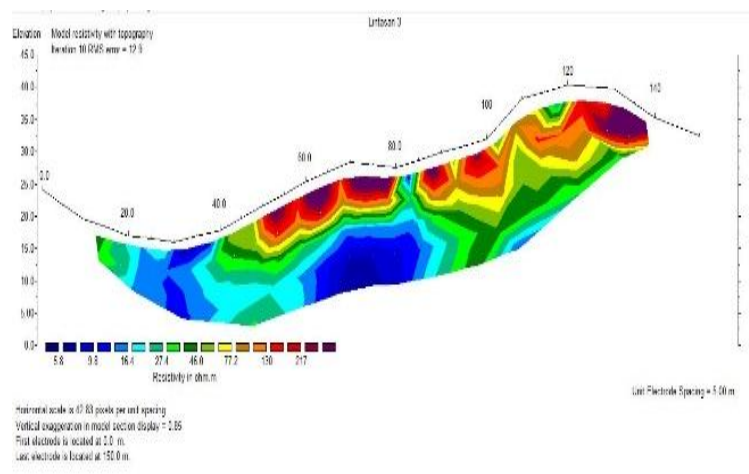

Gambar 6. Penampang 2D resistivitas lintasan 3

Penampang 2D resitivitas bawah permukaan lintasan ketiga memberi gambaran kondisi bawah permukaan. Pada penampang resistivitas 2D lintasan ketiga terlihat distribusi lapisan pasir dengan resistivitas 20-70 $\Omega \mathrm{m}$ terdapat pada jarak 80-140 m kedalaman 10-25 $m$ yang diduga sebagai lapisan akuifer dangkal pada lintasan tiga. hal itu juga terjadi pada Lapisan lempung yang terdistribusi pada jarak 0-80 meter dengan resistivitas 5-20 $\Omega \mathrm{m}$. Lapisan teratas terdiri dari soil dan pasir kuarsa dengan nilai resistivitas 200-300 $\Omega \mathrm{m}$, pada bagian alam lintasan ini terdapat daerah dengan resistivitas rendah yang diakibatkan kandungan air diarea tersebut.

\section{Kesimpulan}

Berdasarkan penampang 2D resistivitas diketahui bahwa susunan lapisan bawah permukaan daerah penelitian tersusun atas tanah penutup atau soil resistivitas 70-300 $\Omega \mathrm{m}$ pada kedalaman 0-5 m, lapisan pasir dengan resistivitas 20-70 $\Omega \mathrm{m}$ pada kedalaman 5-10 m, lapisan lempung dengan resistivitas 5-20 $\Omega \mathrm{m}$ pada kedalaman 10-20 $\mathrm{m}$ dan sisipan gamping pada kedalaman 5-20 m. Sisipan batugamping tidak tersebar merata pada setiap lintasan. Lapisan pasir didugaberperan sebagai akuifer dangkal pada kedalaman 5-10 m merupakanlapisan akuifer bebas.

\section{Saran}

Diperlukan adanya penelitian lebih lanjut untuk mengetahui kualitas air yang terkadung dalam lapisan akuifer dangkal. Hal ini diperlukan untuk mengetahui kandungan logam berat dalam air, karena lokasi penelitian dengan TPA Manggar.

\section{Ucapan Terimakasih}

Ucapan terimakasih disampaikan kepada Pihak LPPM Institut Teknologi Kalimantan yang telah mendanai kegiatan penelitian ini sehingga dapat dilakukan dengan baik. Ucapan terimaksih juga disampaikan pada mahasiswa prodi Fisika Institut Teknologi Kalimantan yang telah membantu kegiatan akusisi data dalam penelitan ini. 


\section{Daftar Pustaka}

[1] Wilson, E.M,Hidrologi Teknik. Institut Teknologi Bandung, Bandung, 1993

[2] Sutandi, M.C,Air Tanah. Universitas Kristen Maranatha, Bandung, 2012

[3] Kurniawan, Basra., Akmam., dan Sudiar, Nofi Yendri "Estimasi Kedalaman Batuan Dasar Di Desa Kampung Manggis Kecamatan Padang Panjang Barat Menggunakan Metode Inversi Robust 2D Data Geolistrik Tahanan Jenis Konfigurasi Wenner", Pillar of Physics, Vol. 1, hal. 49-56, 2014.

[4] Andrias S W, “Aplikasi metode geolistrik resistivitas konfigurasi wenner untuk menentukan struktur tahan di halaman belakang SCC ITS Surabaya, "Jurnal fisika Indonesia, Vol-XIX , No.55, 2015.

[5] Telford, W.M., Geldart, L.P., dan Sheriff, R.E. , Applied Geophysics, 2nd edition, Cambridge University Press, Cambridge, 1990.

[6]As'ari, Seni H J T, Metode geolistrik konfigurasi dipole-dipole untuk identifikasi daerah patahan manado di kecamatan singkil kota manado, Jurnal MIPA UNSRAT Online, Vol2, No.5, pp 99-102, 2016.

[7] Muntaha, Jakaria A.L, Febrian D S, "Identifikasi Struktur Tanah Bawah Permukaan Tempat Pemrosesan Akhir (TPA) Manggar dengan Menggunakan Metode Geolistrik Konfigurasi Schlumberger, "Jurnal Aplikasi Teknik Sipil, Vol-17,No.1, 2019.

[8]Wahyono C.S, W.Utama, N Priyantari, "Penentuan Bidang Gelincir Pada Daerah Rawan Longsor Dengan Menggunakan Metode Geolistrik 2-D Di Desa Lumbang Rejo, Prigen, Pasuruhan, " Program Pasca sarjana Fisika. Jurusan FMIPA ITS, Surabaya, 2013

[9] Peta geologi 